\title{
IoT Based Self-Cleaning and Automated Fault Detection of Solar Panel System
}

\author{
Vamshi Krishna Sabbi
}

\begin{abstract}
Solar photovoltaic panel tends to lose its performance, when foreign particles start accumulating over it. To get panel at its best, frequent cleaning action is required by some means. It would be beyond imagination, if there comes a task to clean entire solar farm covering miles squares and more, hence a better solution is required. Solar photovoltaic panel cleaning system is a robotic system designed to clean solar panel surface; in order to sustain the efficiency. To avoid frequent site visits, robots can be placed in each array, and by further deploying Internet of Things (IoTs), distant monitoring and cleaning can be achieved. The command for the robots can be given by distant operator through the cloud they are connected with. To make this system even smarter, a separate sensing unit shall be installed along with different sensors that can detect the limit of dust deposition and shall automatically order to perform cleaning action. This study presents the need of cleaning system, which is followed by design and fabrication of robot that meets the design specification and required performance. A month-long data is collected and analyzed to formulate and validate the automatic cleaning algorithm in real environment. From this study, it is concluded that, the IoT can be implemented in the solar PV cleaning system which can improve the system performance significantly.
\end{abstract}

Keywords: Performance, Cleaning, Particle Photon, Algorithm, Robot, Internet of Things.

\section{INTRODUCTION}

Power generation from renewable sources has developed significantly in modern age [1,2]. Photovoltaic (PV) is one of the renewable energy sources with the greatest future projection as it possesses features such as simple installation, high reliability, low maintenance cost due to absence of moving parts and zero fuel cost [3]. Solar photovoltaic energy is harnessed from solar radiation; for a mono crystalline solar PV panels under standard test condition, it is seen that only $15-18 \%$ of solar radiation is utilized to produce electricity [4]. Achieving maximum efficiency has been a challenge and this efficiency changes due to several factors like: lower irradiance; higher air mass; higher temperature; regardless of this, solar radiation is failed to be harnessed due to accumulation of foreign particles like dust, bird excrement, snow, and many other [4]. Large scale PV systems are immensely precious on solar panels. Conventionally, the panels are proven to be expensive in large scale PV system [5] Accumulation of dust particle increases the temperature of solar panel up to $10 \%$ resulting decrease in net output power

Revised Manuscript Received on October 31, 2019.

Vamshi Krishna Sabbi, Electronics and Communication Department, Godavari Institute of Engineering \& Technology (Autonomous), Rajahmundry, India. Email: prof.svkrishna@gmail.com
[6]. It not only increases module temperature, but also blocks the solar radiation that can reduce the system efficiency significantly. From an experimental study for two different setups: indoor and outdoor, it is evaluated that the efficiency decreased by around $30-40 \%$, and in particular, moss deposition could reduce the output power by up to $86 \%$ [7]. Making consideration to reviewed facts and figures interlinked with efficiency reduction, significant improvement in the output of the solar panels can be achieved by effective method of cleaning [8].

\section{RESEARCh Methodology}

This section outlines the chronological movement of this study from defining the problems, to ways of addressing it and finally the process of devising a working solution to the stated problem. The detail processes of the adopted methodology are listed below:

\section{A. Literature review and problem identification}

Starting from facts and figures, the need of solar photovoltaic panel cleaning system is identified. Upon coming to conclusion of literature review, the requirements that the prototype must fulfil along with the acceptance criteria was noted down.

\section{B. Idea Generation for fabrication of proposed model}

Furthermore, moving on to Idea Generation process: best cleaning method, movement across the panel and movement across the adjacent panel among different options was chosen and is illustrated by Table 1 .

Table 1: Idea generation with components and method selection.

\begin{tabular}{lll}
\hline Cleaning Method & Movement Across Panel & Movement between adjacent panel \\
\hline Air/Water Jet & Wheels & Three bar mechanism \\
Mop & Suckers & Make a bridge \\
Scrubbing & Rails & Spring System \\
Rollers/Rotational & Caterpillar Tracks & Attachment rails \\
Vacuum & Detachable Pulleys & Flying \\
Wiping & Hover/flying & Big wheels \\
\hline
\end{tabular}

To achieve effective cleaning, roller was selected as the best cleaning method among all other methods. To avoid the stress of cleaner weight and to achieve better mobility, movement across the panel and adjacent panel was expected to be achieved by attaching a separate rail at top and bottom ends. Several designs were sketched, and among them the best design: robotic design was proposed and proceeded towards fabrication process.

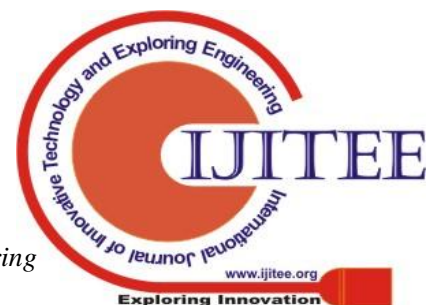




\section{IoT Based Self-Cleaning and Automated Fault Detection of Solar Panel System}

Different designs along with their defects are shown by Table 2 .

The reason for selecting robotic design was primarily associated with its large-scale application from a single unit of it. The requirement of separate power supply for robotic design can easily be addressed by the use of either light weight battery or a separate solar module over the top of it, which can supply the required power.

Table 2: Different design and their defects.

\begin{tabular}{ll}
\hline \multicolumn{1}{c}{ Design } & \multicolumn{1}{c}{ Defects } \\
\hline Chain Sprocket Design & 1. Impracticable for Large array \\
& 2. Sagging of chain \\
Threaded Bar/Nut Design & 1. Fixed System \\
Robotic Design & 2. Slower \\
& 1. Separate Power Supply Required \\
\hline
\end{tabular}

On moving forward with robotic design, engineering dynamics associated with it was discussed using free body diagram as shown in Figure 1. To calculate the torque required, it is assumed that sine component of total weight of robot is exerted at the upper end of rails, whereas the cosine component exerted at the lower end: under equilibrium condition.

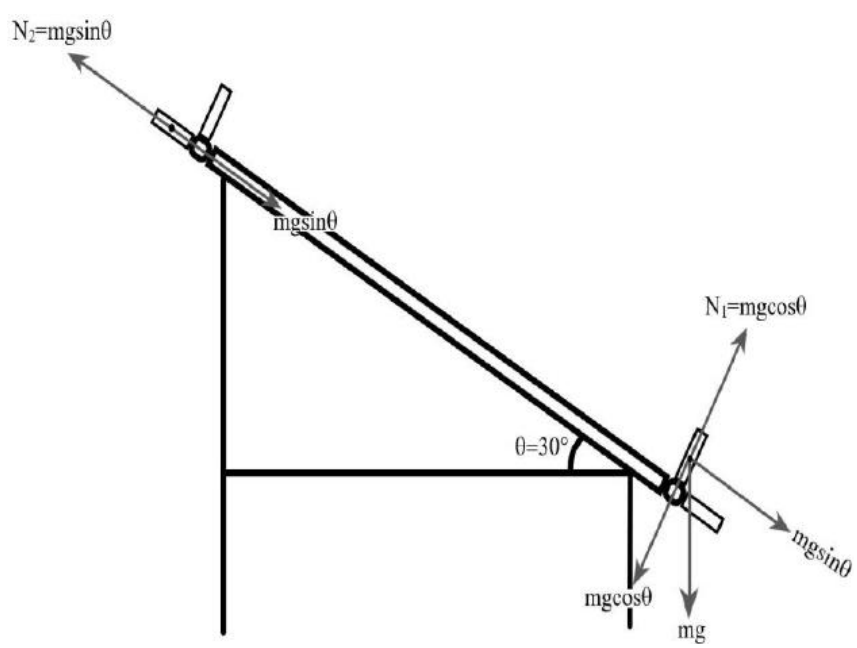

Figure 1: Free body diagram of developed robotic model.

Where, $\mu=0.2$ (the coefficient of friction between mild steel and plastic tyre) [9], $\mathrm{m}=5.37 \mathrm{~kg}$ (mass of robot), $\mathrm{N}=$ Normal Reaction force, $\mathrm{g}=9.8 \mathrm{~m} / \mathrm{s} 2$ (acceleration due to gravity), $\theta=$ Tilt angle, $\tau=$ Required Torque.

The force required on lower part of robotic unit is given by:

$$
\begin{aligned}
& F_{d}=\mu N_{1} \\
& F_{d}=\mu m g \cos \theta
\end{aligned}
$$

The torque required on the lower part of robotic unit is:

$$
\begin{aligned}
& \tau_{d}=F_{d} \times \text { radius of wheel } \\
& F_{d}=0.2 \times 5.37 \times 9.8 \times \cos 30^{\circ}=9.11 \mathrm{~N} \\
& T_{d}=9.11 \times 3.5 \times 10^{-2}=0.3189 \mathrm{Nm}
\end{aligned}
$$

Thus the force and torque required on the lower part of robotic arm is $9.11 \mathrm{~N}$ and $0.3189 \mathrm{Nm}$ respectively. Similarly, for the upper part of robotic arm we calculate force and torque as:

$$
\begin{aligned}
& F_{u}=\mu N_{2} \\
& F_{u}=\mu m g \sin \theta \\
& \tau_{u}=F_{u} \times \text { radius of } \text { wheel } \\
& F_{u}=0.2 \times 5.37 \times 9.8 \times \sin 30^{\circ}=5.2626 \mathrm{~N} \\
& \tau_{u}=F_{u} \times 3.5 \times 10^{-2}=0.1482 \mathrm{Nm}
\end{aligned}
$$

The force and torque required on the upper part of robotic arm is $5.2626 \mathrm{~N}$ and $0.1482 \mathrm{Nm}$ respectively. Hence, to match with the above torque requirement, "Nema 17" with holding torque of $0.45 \mathrm{Nm}$ was selected as the most suitable actuator.

\section{Control system and implementation of autonomous unit}

Following the fabrication of robot, controlling unit for motors was implemented using microcontroller named particle photon, which is capable to connect itself with the internet cloud. Similarly, control unit for autonomous unit is built using particle photon with sensors and transducers. By fetching a month-long data from experimental set up developed, algorithm for autonomous unit is generated using regression analysis and is successfully implemented followed by test runs.

\section{Deployment of Internet of Things (IoT)}

Particle photon is capable of connecting itself with the internet wirelessly using its inbuilt $\mathrm{Wi}-\mathrm{Fi}$ antenna. Autonomous Unit and Robotic Unit communicate each other, and with operator by using a common cloud platform named UBIDOTS. In large solar farm, robotic units are placed on each array, and the communication between all of the robotic units with either autonomous unit or with the human operator, is achieved by the common cloud platform.

\section{E. System execution and performance evaluation}

After the completion of design and fabrication of prototype (autonomous and robotic unit), test runs were made to identify issues and uncertainties associated with it; and

finally, the respective improvements required were concluded.

\section{EXPERIMENTAL SetUP}

In this study, for the development of autonomous operation, an outdoor experimental set up was done at Suryabinayak-09, Bhaktapur, Nepal (27³9'10.3"N, $\left.85^{\circ} 27^{\prime} 37.2^{\prime \prime E}\right)$ using demonstration module $(50 \mathrm{Wp})$ inclined at $30^{\circ}$ facing south. At Stage-I, the performance of totally clean module was monitored and saved on UBIDOTS clouds for further analysis, whereas in Stage-II, the module was demonstrated under the scenario of maximum dust deposition; taking illuminance and output power as parameters.

The fabricated robot along with control unit installed on it was tested on module as shown in Figure $2(\mathrm{a} \& \mathrm{~b})$. The defined zone of operation was successfully programmed on autonomous unit of the system. 

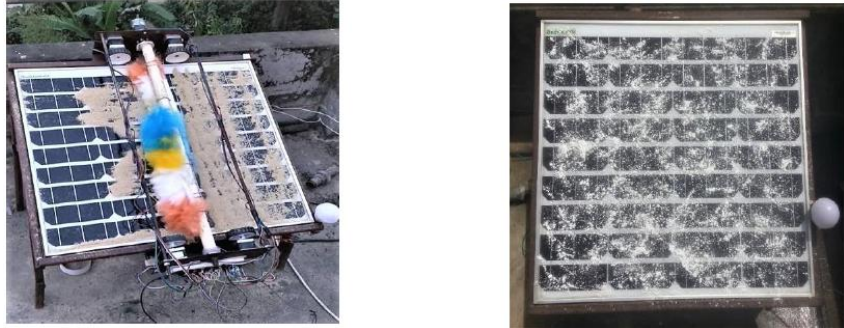

Figure 2: (a\&b) Experimental Set up for the developed model.

\section{OPERATION OF DEVELOPMENT MODEL}

This system consists of two different units: Robotic Unit and Autonomous Unit. The two units communicate through an internet cloud based platform known as UBIDOTS. Robotic Unit acts as a slave unit, as it follows command either from autonomous unit or from UBIDOTS interface directly on operator's demand. The motors move robotic unit back and forth through the rails over the panel. Two limit switches are placed at right and left end to sense the end of the panel array. Also robotic unit consists of rotational brush which cleans the panel as the unit moves.

Autonomous Unit, the master unit sends command to robotic unit to perform cleaning action. This unit comprises of sensors to sense light intensity, dust density, temperature/humidity and output power in order to generate automatic cleaning signal and display the condition of solar panels/farm. The important three variables: illuminance, current and voltage (output power) are taken as the input parameter and real time slope is calculated. This real time slope is compared with slope of the reference line. If the real time slope is less than the reference slope, the master unit sends cleaning command to the slave unit. The autonomous unit keeps on sending command unless the performance of PV is sustained. The entire system: the robotic unit(s) and the autonomous unit are interfaced through a cloud-based platform named UBIDOTS. After successful connection of particle photon or any other hardware, data can be stored, manipulated, visualized in real time, not only that it can generate an alert signal, if anything goes out of track [10].
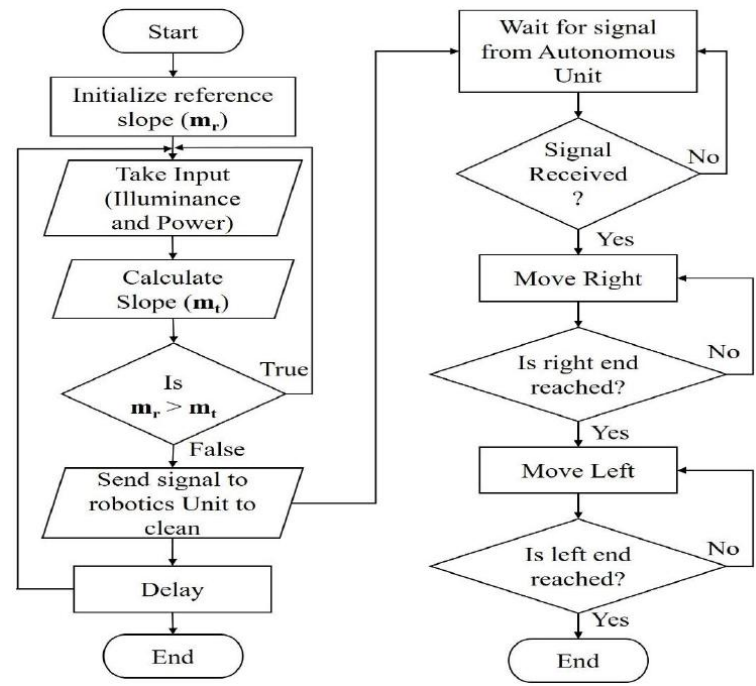

Figure 3: Flowchart of Overall Developed model.

In the section of devices, real time data is monitored showing each and every variable with real time values associated with them; which can be depicted by Figure 4 . In the dashboard section, acquired data is visualized in different forms like line, chart, double axis, scatter plot, histogram, and bars as shown in Figure 5. In the same section, operator can send the cleaning signal through a switch as shown in Figure 7. "Event" is a feature in UBIDOTS which notifies the user through email, text message, telegram or web hook under specified receiving network address, when certain parameters exceed the limit as shown in Figure 5 and 6:

\section{DATA ANALYSIS AND IMPLEMENTATION ON AUTONOMOUS Unit}

A month-long data was processed using data analysis techniques: scaling, transformation and feature selection, and is followed by regression analysis. Line of best fit for both: with and without dust scenario, was compared as shown in Figure 8. The equation of line of best fit were $y=-2.6282350$ $+0.0009607 \mathrm{x}$ for a clean panel; and $\mathrm{y}=1.2287555+$ $0.0002992 x$ for a panel with dust.

From above regression analysis, automatic cleaning algorithm was generated by using slope of these two lines of best fit. A new parameter named slope of reference line was calculated by taking average of those two lines as follows:

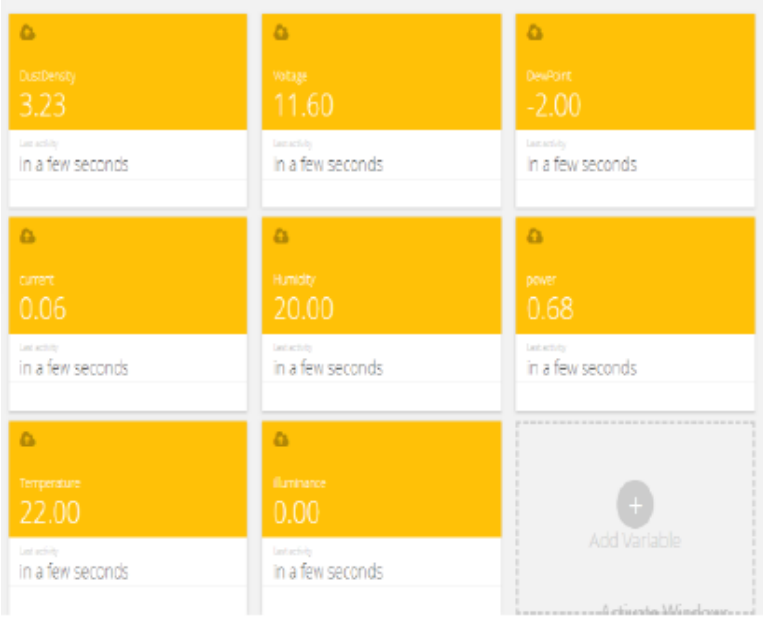

Figure 4: Real Time Data of Different Variables.

Slope of Reference Line $(\mathrm{mr})=\frac{\text { Slope without dust }(\mathrm{mc})+\text { Slope with dust }(\mathrm{md})}{2}$

A new parameter named real time slope is introduced which is the measure of ratio of real time power to real time Illuminance input and defined as:

$$
\text { Real Time Slope }(\mathrm{mt})=\frac{\text { Real Time Power }(\mathrm{P}(\mathrm{t}))}{\text { Real Time Illuminance }(\mathrm{I}(\mathrm{t}))}
$$

Finally, condition for the cleaning system whether to perform cleaning action or not is defined as: if real time slope is lesser than reference slope, cleaning action is performed else cleaner returns/remains to rest position.

Published By:

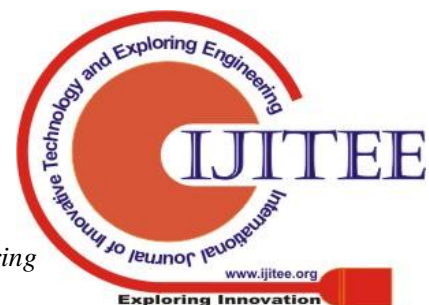




\section{IoT Based Self-Cleaning and Automated Fault Detection of Solar Panel System}

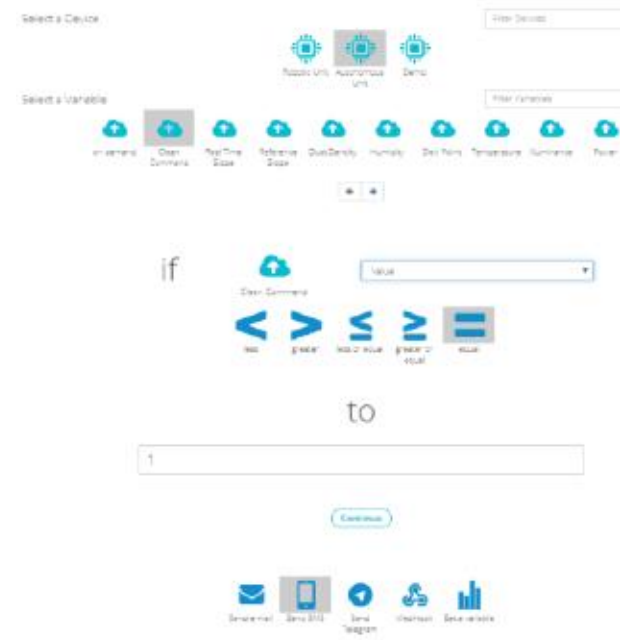

Figure 5: Event created to send SMS under violation of Condition set.

\section{System Evaluation}

The evaluation of the prototype developed for IoT based Solar Photovoltaic Cleaning System is evaluated under requirements set at the initial state of prototype development and can be illustrated as shown in Table 3 .

\section{CONCLUSION AND NECESSARY IMPROVEMENTS}

IoT based Solar Photovoltaic Cleaning System consists of two units: Robotic and Autonomous along with cloud-based Man machine interface. These two units communicate each other via same cloud-based interface known as UBIDOTS. The main driving objective of the project was to clean the solar PV module with least human effort for a large solar farm.

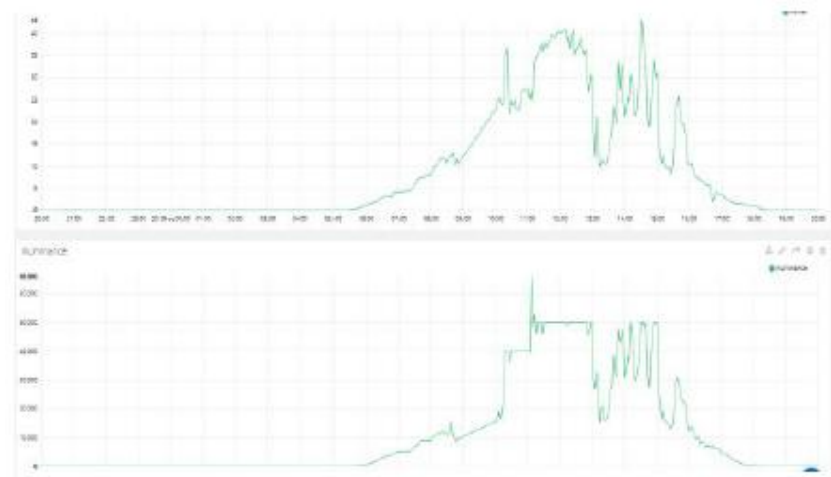

Figure 6: Dashboard Showing Output Power and Illuminance during different time.

\section{clean-commano}

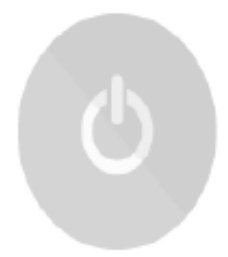

off
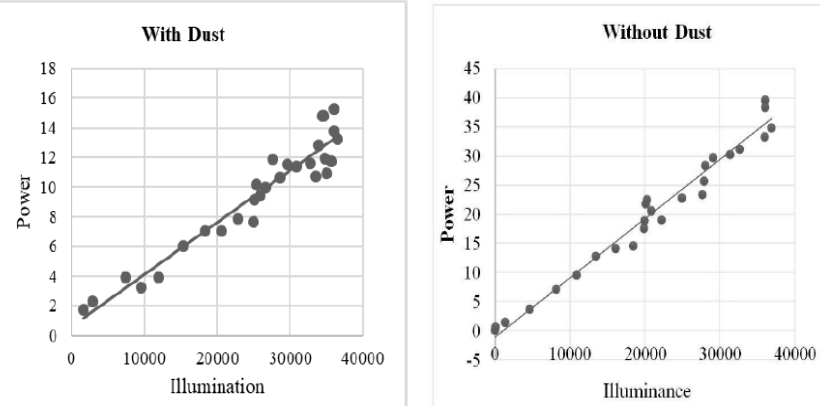

Figure 8 (a \&b): Output Characteristics of Prototypic PV Module under Dusty and Clean Condition.

For a distant solar farm site, autonomous cleaner makes cleaning job easier, where cleaning action is achieved without making travel to the site. The elimination of water reduces consumable costs, however bird excrement and tough dirt would be still an issue.

Table 3 illustrates most of the design requirements are met and Table 4 illustrates improvements required in current prototype. The innovation of project is autonomous cleaning, which can be proven most effective for large solar farm located in semi-arid areas, where frequent cleaning is required due to sand deposition.

The autonomous unit generates autonomous signal at the time of need and commands robotic units placed in every solar array.

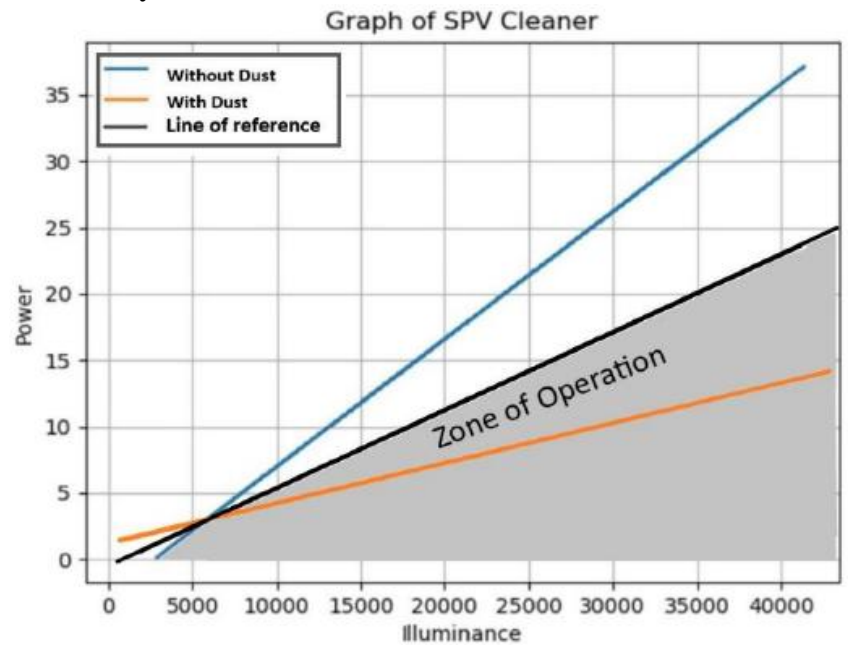

Figure 9: Output Characteristics of Prototypic PV Module under Dusty and Clean Condition.

Table 3: Evaluation of Prototype Developed. Key: $\mathrm{Y} / \mathrm{P} / \mathrm{N}=$ Yes/Partially/No)

\begin{tabular}{|c|c|c|c|}
\hline S.No & Requirements & Met? & Discussion \\
\hline 1 & $\begin{array}{l}\text { Must be able to clean the entire } \\
\text { surface area of a } 660 \mathrm{~mm} * 600 \mathrm{~mm} \\
\text { demonstration solar PV module }\end{array}$ & $\mathrm{Y}$ & $\begin{array}{l}\text { The prototype is capable of cleaning entire } \\
\text { surface of demonstration panel. }\end{array}$ \\
\hline 2 & $\begin{array}{l}\text { Must be able to clean one whole } \\
\text { solar panel array }\end{array}$ & $\mathrm{Y}$ & $\begin{array}{l}\text { Attachment Rails at the edge of panel makes } \\
\text { cleaner to move effectively through entire solar } \\
\text { panel array }\end{array}$ \\
\hline 3 & $\begin{array}{l}\text { Must not damage solar panels } \\
\text { during cleaning. }\end{array}$ & $\mathrm{Y}$ & $\begin{array}{l}\text { Cleaning roller softly touches panel surface } \\
\text { without any mechanical stress. Soft brushes } \\
\text { made up of animals wool(ostrich, sheep) can } \\
\text { improve the performance }\end{array}$ \\
\hline 4 & $\begin{array}{l}\text { Able to clean panels without a } \\
\text { water supply }\end{array}$ & $P$ & $\begin{array}{l}\text { Can effectively clean dry dust, however bird } \\
\text { excrement and tough dirt is still an issue }\end{array}$ \\
\hline
\end{tabular}

Published By: Blue Eyes Intelligence Engineering 


\begin{tabular}{|c|c|c|c|}
\hline 5 & $\begin{array}{l}\text { Should be able to clean more than } \\
\text { one type of solar panel }\end{array}$ & $\mathrm{P}$ & $\begin{array}{l}\text { For differently sized module, respective sizes of } \\
\text { cleaning brushes (length wise) must be used. }\end{array}$ \\
\hline \multicolumn{4}{|c|}{ Physical Characteristics } \\
\hline 1 & $\begin{array}{l}\text { Must not require anyone working at } \\
\text { height }\end{array}$ & $\mathrm{Y}$ & $\begin{array}{l}\text { Once cleaner is placed on the rails, it cleans } \\
\text { entire array without human effort. }\end{array}$ \\
\hline 2 & $\begin{array}{l}\text { Must be able to withstand } \\
\text { vibrations encountered during } \\
\text { transportation }\end{array}$ & $\mathrm{P}$ & $\begin{array}{l}\text { In prototype, motors are attached with GI Sheet } \\
\text { with chemical named bond tite, which resulted } \\
\text { strong join. }\end{array}$ \\
\hline \multicolumn{4}{|c|}{ Autonomous System } \\
\hline 1 & $\begin{array}{l}\text { Must be able to detect reduced } \\
\text { efficiency of SPV with respect to } \\
\text { illuminance and generate cleaning } \\
\text { signal }\end{array}$ & $\mathrm{P}$ & $\begin{array}{l}\text { Generates cleaning signal, when efficiency } \\
\text { reduction exceeds specified limit, for better } \\
\text { performance better sensors can be used. }\end{array}$ \\
\hline 2 & $\begin{array}{l}\text { Must be able to command robotic } \\
\text { unit to initiate cleaning action } \\
\text { wirelessly }\end{array}$ & $\mathrm{Y}$ & $\begin{array}{l}\text { Autonomous unit- robotic unit communication } \\
\text { as well operator- robotic unit communication is } \\
\text { achieved through IoT cloud platform. }\end{array}$ \\
\hline
\end{tabular}

Table 4: Issues/ uncertainties and improvements.

\begin{tabular}{|c|c|c|}
\hline S.N & Issues/uncertainties & Improvements \\
\hline \multicolumn{3}{|c|}{ Robotic Unit } \\
\hline 1 & Weight Issue & $\begin{array}{l}\text { I. Robotic Frame shall be made of metal of } \\
\text { comparatively lesser density than GI sheet }\end{array}$ \\
\hline & & $\begin{array}{l}\text { II. Instead of using four stepper motors, two motor } \\
\text { with higher torque can be used }\end{array}$ \\
\hline 2 & Cleaning Brush & $\begin{array}{l}\text { Softer cleaning brushes with larger number of fibers } \\
\text { shall be replaced }\end{array}$ \\
\hline 3 & Water Proof Casing & $\begin{array}{l}\text { Water proof casing shall be provided to motors and } \\
\text { circuitry to prevent damage during rainfall }\end{array}$ \\
\hline 4 & Effective movement & $\begin{array}{l}\text { Ball bearings and extra tires shall be placed for } \\
\text { smooth movement of robotic unit }\end{array}$ \\
\hline \multicolumn{3}{|c|}{ Autonomous Unit } \\
\hline 1 & $\begin{array}{l}\text { Limitation of Illuminance Sensor (up } \\
\text { to } 40000 \text { ) }\end{array}$ & $\begin{array}{l}\text { Reference solar cell or Pyranometer can be used for } \\
\text { wide range operation[11] }\end{array}$ \\
\hline 2 & Sensor Calibration & More précised calibration of sensors shall be done \\
\hline
\end{tabular}

In contrast, the whole project features on demand as well as autonomous cleaning of solar panel ranging from small scale to large scale solar farm.

\section{REFERENCES}

1. K. Komoto, E. Cunow, C. Breyer, D. Faiman, K. Megherbi, and P. van der Vleuten, "IEA PVPS Task8: Study on Very Large Scale Photovoltaic (VLS-PV) Systems," in 2012 38th IEEE Photovoltaic Specialists Conference, 2012, pp. 001778-001782: IEEE.

2. A. K. Mondal and K. Bansal, "A brief history and future aspects in automatic cleaning systems for solar photovoltaic panels," Advanced Robotics, vol. 29, no. 8, pp. 515-524, 2015.

3. W. Chine, A. Mellit, A. M. Pavan, and S. A. Kalogirou, "Fault detection method for grid- connected photovoltaic plants," Renewable Energy, vol. 66, pp. 99-110, 2014.

4. N. Khadka, B. Adhikari, A. Bista, and A. Shrestha, "Solar Panel Cleaner Technology: A Review."

5. M. Mazumder et al., "Electrostatic removal of particles and its applications to self-cleaning solar panels and solar concentrators," in Developments in Surface Contamination and Cleaning: Elsevier, 2011, pp. 149-199.

6. L. Dorobantu, M. Popescu, and C. Popescu, "Yield loss of photovoltaic panels caused by depositions," in Advanced Topics in Electrical Engineering (ATEE), 2011 7th International Symposium on, 2011, pp. 1-4: IEEE.

7. S. A. Sulaiman, A. K. Singh, M. M. M. Mokhtar, and M. A. Bou-Rabee, "Influence of dirt accumulation on performance of PV panels," Energy Procedia, vol. 50, pp. 50-56, 2014.

8. A. Hassan, U. A. Rahoma, H. K. Elminir, and A. Fathy, "Effect of airborne dust concentration on the performance of PV modules," J. Astron. Soc. Egypt, vol. 13, no. 1, pp. 24-38, 2005.

9. Tribology-abc. (8 July). Coefficient of friction, Rolling resistance and Aerodynamics. Available: http://www.tribology-abc.com/abc/cof.htm

10. ubidots. (Feburary 24). IoT and Cloud Tools. Available: https://ubidots.com/platform/

11. J. Meydbray, E. Riley, L. Dunn, K. Emery, and S. Kurtz, "Pyranometers and Reference Cells: Part 2: What Makes the Most Sense for PV Power Plants?," National Renewable Energy Lab (NREL), vol. Preprint-NREL/JA-5200-56718, 2012. 